\title{
PRODUÇÃO DE FORRAGEM DO CAPIM-TANZÂNIA SOB INTERVALOS DE CORTE E DOSES DE POTÁSSIO ${ }^{1}$
}

\author{
Forage production of Tanzania grass under cutting intervals and potassium doses
}

\author{
Milena Rízzia Ferreira de Souza ${ }^{2}$, José Cardoso Pinto³, Itamar Pereira de Oliveira ${ }^{4}$, \\ Joel Augusto Muniz ${ }^{5}$, Gudesteu Porto Rocha ${ }^{3}$, Antônio Ricardo Evangelista ${ }^{3}$
}

\begin{abstract}
RESUMO
O experimento foi conduzido em campo, numa área estabelecida com o capim-tanzânia em novembro de 1997, em Lavras MG, de agosto de 2001 a maio de 2002. Objetivou-se avaliar a influência de quatro intervalos de corte (4, 6, 8 e 10 semanas) e três doses de $\mathrm{K}_{2} \mathrm{O}(0,100$ e $200 \mathrm{~kg} / \mathrm{ha})$ na produção de forragem de Panicum maximum Jacq. cv. Tanzânia 1 . O experimento, um fatorial 4 x 3, teve como delineamento experimental blocos ao acaso, com quatro repetições. A adubação de manutenção constituiu de $\mathrm{N}$ de 150 $\mathrm{kg} / \mathrm{ha}$, como sulfato de amônio, de $\mathrm{P}_{2} \mathrm{O}_{5}$ de $60 \mathrm{~kg} / \mathrm{ha}$, como superfosfato simples, e de $\mathrm{K}_{2} \mathrm{O}$ de $50 \mathrm{~kg} / \mathrm{ha}$, como cloreto de potássio. A adubação potássica foi aplicada a lanço, nas entrelinhas do capim-tanzânia, sendo em duas aplicações. Registrou-se incrementos lineares da altura de perfilho e da produção de MS do capim-tanzânia com o aumento dos intervalos de corte. A densidade de perfilhos e a relação folha/colmo foram independentes dos tratamentos aplicados.
\end{abstract}

Termos para indexação: Altura e densidade de perfilho, Panicum maximum, relação folha/colmo.

\section{ABSTRACT}

The experiment was carried out in a field previously seeded in November of 1997, with Tanzania grass, at Lavras-MG, Brazil from August of 2001, to May of 2002, with the objective to evaluate the influence of four cutting intervals (4, 6, 8 and 10 weeks) and three $\mathrm{K}_{2} \mathrm{O}$ doses $(0,100$ and $200 \mathrm{~kg} / \mathrm{ha})$ on growth and forage production of Panicum maximum Jacq. cv. Tanzania 1 . Soil analysis of the experimental area was made and a maintenance fertilization was done, by applying $150 \mathrm{~kg} / \mathrm{ha}$ of N, as ammonium sulfate, $60 \mathrm{~kg} /$ ha of $\mathrm{P}_{2} \mathrm{O}_{5}$, as simple superphosphate, and $50 \mathrm{~kg} / \mathrm{ha}$ of $\mathrm{K}_{2} \mathrm{O}$, as potassium chloride. The treatments were combined in a factorial $4 \times 3$ design, in randomized blocks with four replications. Potassium fertilization was done in broadcast method between lines of tanzania grass, in two applications. Linear increments of tiller height and dry matter production of tanzania grass were observed by increasing the cutting intervals. The tiller density and the leaf/stem ratio were independent of the applied treatments.

Index terms: Tiller density and height, Panicum maximum, leaf/stem ratio.

\section{(Recebido em 23 de março de 2005 e aprovado em 29 de setembro de 2006)}

\section{INTRODUÇÃO}

O Brasil apresenta cerca de $30 \%$ de todo o seu território coberto por pastagens (FAO, 2000), que se constituem em fonte de alimento de baixo custo da grande maioria do rebanho nacional. Calcula-se que aproximadamente $89 \%$ do plantel de bovinos brasileiros sejam manejado única e exclusivamente em pastagens (ANUALPEC, 2000).

O lançamento comercial do capim-tanzânia (Panicum maximum Jacq. cv. Tanzânia - 1) ocorreu em 1990, destacando-se pelo seu alto potencial produtivo em relação ao capim-colonião, em solos de boa fertilidade (ABREU, 1999). Apesar de já existirem muitas pesquisas conduzidas com o capim-tanzânia, ainda existe necessidade de informações quanto às suas exigências nutricionais (BELARMINO, 2001) e a sua morfogênese em condições de campo (SANTOS, 1997).

De outra forma, também existe uma grande carência de informações sobre a ecofisiologia das espécies forrageiras tropicais para direcionar e orientar práticas sustentáveis de manejo. A definição de estratégias que permitam maior eficiência no manejo de pastagens tropicais, através de um maior aproveitamento do potencial de produção das plantas forrageiras, requer a compreensão de seu comportamento morfofisiológico e resposta à adubação, minimizando o processo de degradação da pastagem em uso. A obtenção dessas informações é

\footnotetext{
${ }^{1}$ Parte da Dissertação de Mestrado do primeiro autor para a obtenção do título de Mestre em Zootecnia, Forragicultura e Pastagens, Universidade Federal de Lavras/UFLA

'Zootecnista, Professora do Departamento de Zootecnia da Universidade Estadual de Goiás/UEG - Unidade Universitária de São Luis de Montes Belos/SLMB aluna do curso de mestrado em Zootecnia da Universidade Federal de Lavras/UFLA - Cx. P. 3037 - $37200-000$ - Lavras, MG milena.rizzia@bol.com.br

${ }^{3}$ Engenheiro Agrônomo, DSc, Professor do Departamento de Zootecnia/DZO da Universidade Federal de Lavras/UFLA - Cx. P. 3037 - $37200-000$ Lavras, MG - Bolsista do CNPq - josecard@ufla.br; gudesteu@ufla.br; aricardo@ufla.br

${ }^{4}$ Engenheiro Agrônomo, PhD, Pesquisador da EMBRAPA Arroz e Feijão - Rodovia GO-462, Km 12 - Cx. P. 179 - $75375-000$ - Santo Antônio de Goiás, GO - itamar@cnpaf.embrapa.br

${ }^{5}$ Engenheiro Agrônomo, DSc, Professor do Departamento de Ciências Exatas/DEX da Universidade Federal de Lavras/UFLA - Bolsista do CNPq joamuniz@ufla.br
} 
fundamental para se definir o momento mais oportuno para a entrada e saída dos animais em qualquer situação de pastejo, especialmente em sistemas de lotações intermitentes e a altura e/ou a melhor disponibilidade de forragem, relacionando o melhor balanço possível entre os desempenhos produtivos da planta forrageira e do animal.

Em uma comunidade de gramíneas forrageiras a unidade vegetativa básica é o perfilho (HODGSON, 1990), sendo o perfilhamento o mecanismo de sobrevivência a desfolhas sucessivas das gramíneas de uma pastagem e o principal meio de formação e regeneração de área foliar (LEMAIRE \& CHAPMAN, 1996).

A colheita eficiente e a utilização da forragem produzida são altamente dependentes da freqüência e intensidade com que as folhas individuais dos perfilhos são desfolhadas relativamente à sua longevidade (LEMAIRE \& CHAPMAN, 1996). O equilíbrio desse processo, influenciado e determinado por condições e estruturas do pasto, resulta na produção de matéria seca (MS) passível de ser colhida e determina os níveis de eficiência ou aproveitamento da forragem produzida (HODGSON, 1990).

O potássio $(\mathrm{K})$ não tem função estrutural na planta, mas é um ativador de funções enzimáticas e de manutenção da turgidez das células (RAIJ, 1991), sendo absorvido pelas plantas em grandes quantidades. Está fortemente associado à maior resistência das plantas a condições adversas, tais como baixa disponibilidade de água, extremos de temperatura e redução da incidência de doenças e ataques de insetos (FURTINI NETO et al., 2001).

Em relação apenas à adubação potássica, não estando associada à adubação nitrogenada, em gramíneas forrageiras a pasto, apesar dos muitos trabalhos já conduzidos, em sua maioria indicam pouca resposta destas plantas a este nutriente. Existe, ainda, uma defasagem entre as informações de pesquisa e a realidade atual, em solos mais esgotados e/ou com maiores produtividades, o que acarreta, geralmente, aplicações insuficientes de potássio às culturas (RAIJ, 1991).

Objetivou-se avaliar a influência de intervalos de corte e doses de potássio no desenvolvimento e produção de forragem de Panicum maximum Jacq. cv. Tanzânia-1, em pastagem em seu quinto ano de implantação.

\section{MATERIAL E MÉTODOS}

O experimento foi conduzido a campo em uma área estabelecida em novembro de 1997 com o capim-tanzânia, nas dependências do Departamento de Zootecnia da Universidade Federal de Lavras (UFLA), situada no município de Lavras - MG.

O solo da área experimental é classificado como Latossolo Vermelho distroférrico, textura muito argilosa e relevo levemente ondulado, apresentando, na análise química, valor de $\mathrm{pH}$ em $\mathrm{CaCl}_{2}$ de 5,6; saturação por bases de 50\%; saturação de $\mathrm{Al}$ de $2,0 \%$ e teores de $\mathrm{P}$ e K, extraídos pelo método Mehlich-1, disponíveis de 3 e $27 \mathrm{mg} / \mathrm{dm}^{3}$.

$\mathrm{O}$ experimento consistiu de um fatorial $4 \times 3$, correspondendo a quatro intervalos de corte $(4,6,8$ e 10 semanas) e três doses de $\mathrm{K}_{2} \mathrm{O}(0 ; 100$ e $200 \mathrm{~kg} / \mathrm{ha})$ aplicado como cloreto de potássio, no delineamento de blocos ao acaso, com quatro repetições. Cada bloco possuía 12 parcelas de 20 e 7,2 $\mathrm{m}^{2}$, respectivamente de áreas total e útil cada, constituídas por 10 linhas do capim-Tanzânia espaçadas de 0,40 m e com 5,0 m de comprimento.

Em virtude dos resultados da análise de solo, não foi aplicado calcário e a adubação de manutenção foi realizada com $\mathrm{N}, \mathrm{P}_{2} \mathrm{O}_{5}$ e $\mathrm{K}_{2} \mathrm{O}$ de 150,60 e $50 \mathrm{~kg} / \mathrm{ha}$, respectivamente (CFSEMG, 1999). O N, como sulfato de amônio, foi parcelado em três aplicações, ao passo que o $\mathrm{P}_{2} \mathrm{O}_{5}$, como superfosfato simples, e o $\mathrm{K}_{2} \mathrm{O}$, como cloreto de potássio, foram aplicados em dose única após o corte de limpeza, efetuado em outubro de 2001.

Um mês após o corte de limpeza efetuou-se o corte de uniformização da forragem, com roçadeira costal motorizada, e a adubação de manutenção, iniciando-se em seguida o período experimental, quando foram realizados cortes manuais, com cutelos, em número variável de acordo com os intervalos de corte de 4, 6, 8 e 10 semanas. No início desse período, em novembro de 2001, foi aplicada parte do adubo potássico por tratamento, dividindo-se as aplicações em novembro/2001 e no final de janeiro/2002, juntamente com as duas terças partes da adubação nitrogenada.

A altura das plantas foi medida do nível do solo até a altura do horizonte visual das folhas, em cinco pontos da área útil de cada parcela (OLIVEIRA et al., 2000).

A densidade de perfilhos (perfilhos $/ \mathrm{m}^{2}$ ) foi estimada através da contagem dos perfilhos na área útil da parcela, selecionando-se aleatoriamente três linhas pelo lançamento de um retângulo de ferro de $40 \mathrm{~cm}$ x $30 \mathrm{~cm}\left(0,12 \mathrm{~m}^{2}\right)$.

Foram realizadas colheitas manuais de forragem, na altura aproximada de $5,0 \mathrm{~cm}$ acima do solo na área útil, deixando-se como bordadura duas linhas de cada margem e um metro de cada cabeceira das parcelas. Essa forma de corte drástica nos tratamentos, pode ter influenciado no tratamento com menor intervalo de corte. Foram retiradas 
aleatoriamente duas amostras, uma de 20 perfilhos para a determinação da relação folha/colmo e a outra, de aproximadamente $500 \mathrm{~g}$ de forragem, colocada em sacos de papel, pesada e levada à estufa de ventilação forçada a $65^{\circ} \mathrm{C}$ pelo período de 72 horas, para a estimativa do teor e da produção de MS. As amostras foram moídas em moinho do tipo Willey em peneira de 30 mesh, retirando-se 3,0 $\mathrm{g}$ deste material que foram levados à estufa a $105^{\circ} \mathrm{C}$ para a determinação da $\mathrm{MS}$ a $105^{\circ} \mathrm{C}$ (SILVA, 1981).

Para a determinação da relação folha/colmo, foram destacadas as lâminas foliares dos colmos, sendo ambas as frações acondicionadas separadamente em sacos de papel, identificadas e submetidas à secagem em estufa de ventilação forçada, a $65^{\circ} \mathrm{C}$, por 72 horas. A partir das massas secas de lâminas foliares e de colmos foi estimada a relação folha/colmo.

As análises estatísticas dos resultados foram efetuadas pelas análises de variância e regressão, através do programa estatístico Sisvar, versão 4.3 (FERREIRA, 2003).

\section{RESULTADOS E DISCUSSÃO}

Foram observadas diferenças significativas nas produções de MS do capim-tanzânia em função dos intervalos de corte $(\mathrm{P}<0,01)$ e das doses de $\mathrm{K}_{2} \mathrm{O}(\mathrm{P}<0,05)$. Não foram detectadas diferenças significativas na interação adubação x intervalo de corte. Houve aumento linear da produção de MS do capim-tanzânia em função dos intervalos de corte, verificando-se acréscimo de 340 $\mathrm{kg} / \mathrm{ha}$ de MS para cada semana de intervalo entre cortes (Figura 1), cujos valores variaram de 6,74 a 8,67 t/ha, respectivamente, para plantas colhidas com 4 e 10 semanas.

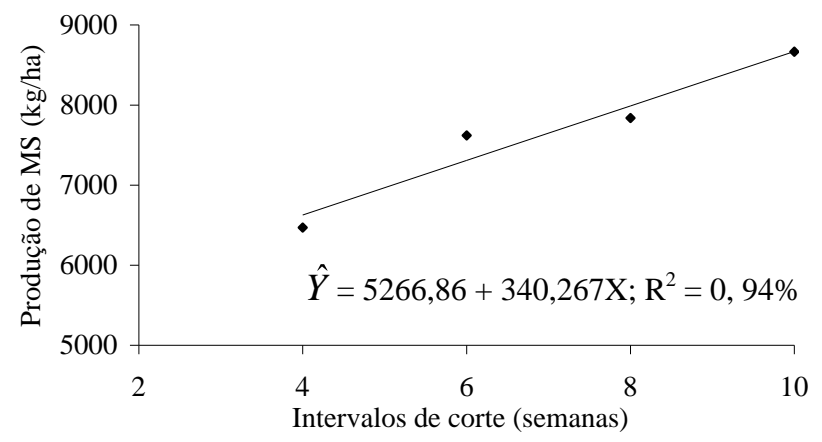

FIGURA 1 - Produção de MS do capim-tanzânia em função dos intervalos de corte.
Da mesma forma, também houve incremento linear da produção de MS em função da adubação potássica, correspondente a $7,978 \mathrm{~kg} / \mathrm{ha}$ de MS para cada quilograma de $\mathrm{K}_{2} \mathrm{O}$ aplicado (Figura 2). Isto decorre da atuação do potássio no metabolismo do nitrogênio, na promoção do crescimento dos tecidos meristemáticos e no controle dos movimentos estomáticos da planta, que é essencial para o funcionamento normal dos processos metabólicos, dentre eles a fotossíntese (CAMARGO \& SILVA, 1975). Essas três funções estão diretamente ligadas à formação da parte estrutural da planta, apresentando melhor resposta desta ao nitrogênio quando associado ao potássio.

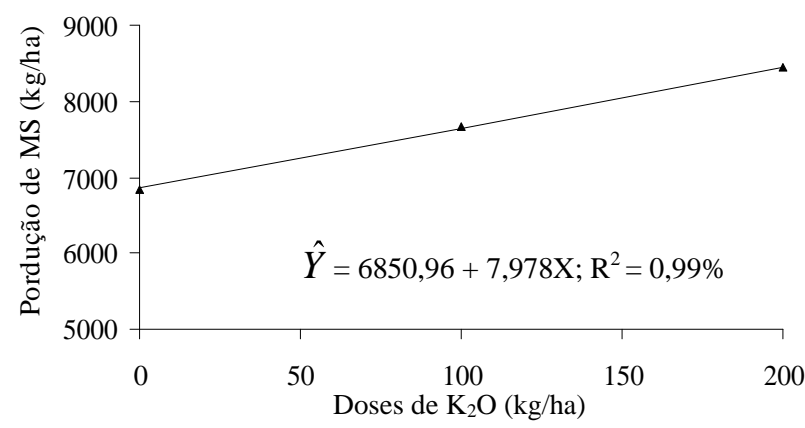

FIGURA 2 - Produção de MS do capim-tanzânia em função das doses de $\mathrm{K}_{2} \mathrm{O}$.

Em relação às doses de $\mathrm{K}_{2} \mathrm{O}$, o presente trabalho proporcionou dados que diferem dos obtidos por Mattos \& Monteiro (1998), com Brachiaria brizantha sob doses do elemento, para os quais a produção de MS da parte aérea dessa gramínea apresentou uma relação quadrática entre o potássio fornecido e a produção alcançada. A máxima produção de MS foi observada, naquele trabalho, entre as doses de 132,50 e 144,84 kg/ha de $\mathrm{K}_{2} \mathrm{O}$.

Carvalho et al. (2001), trabalhando com o capimtanzânia em três alturas $(15 ; 24$ e $60 \mathrm{~cm})$, obtiveram produções de $2.673 ; 2.981$ e $4.255 \mathrm{~kg} / \mathrm{ha} /$ corte de MS, respectivamente. Comparando-se os dados destes autores com esta pesquisa, foi registrado no maior intervalo de corte (10 semanas), alturas de perfilhos do capim-tanzânia de $52 \mathrm{~cm}$ (Figura 3), obtendo-se a produção de MS de 8.670 $\mathrm{kg} / \mathrm{ha}$, proveniente da soma da colheita de dois cortes da forragem. Já o menor intervalo de corte (4 semanas) possibilitou uma altura média de $18 \mathrm{~cm}$ (Figura 3), com produção de MS de $6.740 \mathrm{~kg} / \mathrm{ha}$, proveniente da soma da colheita de 6 cortes da forrageira, valores bem acima dos encontrados por aqueles autores. 


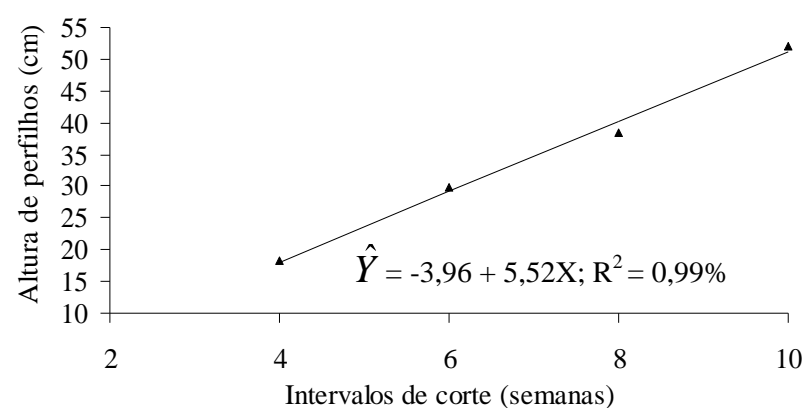

FIGURA 3 - Altura de perfilhos do capim-tanzânia em função dos intervalos de corte.

A análise de variância não revelou influência significativa dos intervalos de corte e das doses de potássio na densidade de perfilhos do capim-tanzânia. Foram obtidos valores de altura de $32 ; 35$ e $36 \mathrm{~cm}$, e densidade de perfilhos de 1337; 1350 e 1338 por $\mathrm{m}^{2}$, da menor para a maior dose de $\mathrm{K}_{2} \mathrm{O}$, respectivamente. Em relação aos intervalos de corte, a densidade de perfilhos apresentou valores de 1375; 1392; 1333 e 1267 por $\mathrm{m}^{2}$, do menor para o maior intervalo, respectivamente.

A baixa densidade de perfilhos pode ter ocorrido, possivelmente, em razão de maior compactação do solo da área experimental com cinco anos de estabelecida, o que dificulta o desenvolvimento radicular da planta e, por conseguinte, a emissão de novos perfilhos. Os fatores climáticos também podem ter contribuído para a ocorrência dessa baixa população de perfilhos. Essa forrageira apresenta as melhores respostas de produção em temperaturas entre 25 e $35^{\circ} \mathrm{C}$ (ARONOVICH, 1995). Durante o período experimental, as temperaturas máxima, média e mínima foram em torno de $27,21 \mathrm{e} 16^{\circ} \mathrm{C}$.

Para a relação folha/colmo do capim-tanzânia, a análise de variância não revelou significância da influência dos intervalos de corte e das doses de potássio. Nos intervalos de 4, 6, 8 e 10 semanas os valores encontrados para a relação folha/colmo foram de 1,69; 1,78; 1,85 e 1,95, respectivamente. Para as doses de $\mathrm{K}_{2} \mathrm{O}$ de 0,100 e $200 \mathrm{~kg}$ / ha, estes valores foram iguais a 1,$79 ; 1,86$ e 1,86, respectivamente.

De uma maneira geral, a relação folha/colmo diminui com o avanço da idade da planta, como consequiência do alongamento do colmo, tornando este componente predominante na forragem disponível, conferindo baixo valor nutritivo à mesma. $\mathrm{O}$ aumento da relação folha/colmo no presente estudo deve-se provavelmente ao reduzido alongamento do colmo, inclusive com ausência de florescimento no período.
Costa \& Oliveira (1997), trabalhando em condições de campo, avaliaram o efeito das idades de corte de 28, 42, 56, 70, 84 e 98 dias em capim-tobiatã (Panicum maximum Jacq. cv. Tobiatã). Os autores verificaram que a eliminação dos meristemas apicais foi diretamente proporcional à idade das plantas. Comparado a este trabalho, nota-se que houve semelhança ao vigor da rebrota que foi significativamente afetado pela idade da planta, sendo as maiores produções obtidas com os cortes aos 42 (1,89 t/ha) e 56 (1,55 t/ha). Com a eliminação dos meristemas apicais, a recuperação da planta se dá às custas de brotações de gemas axilares ou basilares que se constitui em uma recuperação mais lenta, sendo menos satisfatória e produtiva, acarretando no alongamento de colmos e demora na produção de folhas.

\section{CONCLUSÕES}

Os intervalos de corte e as doses de potássio proporcionaram aumentos na altura de perfilho e na produção de MS, porém não influenciaram na densidade de perfilhos e na relação folha/colmo do capim-tanzânia.

\section{REFERÊNCIAS BIBLIOGRÁFICAS}

ABREU, J. B. R. Produção e nutrição dos capins tanzânia1 e marandu em função dos estádios de crescimento e adubação nitrogenada. 1999. 99 f. Tese (Doutorado) - Escola Superior de Agricultura Luiz de Queiroz, Piracicaba, 1999.

ANUALPEC. Anuário da pecuária brasileira. São Paulo: ENP Consultoria e Comércio/Argos, 2000. 392 p.

ARONOVICH, S. O capim colonião e outros cultivares de Panicum maximum Jacq.: introdução e evolução do uso no Brasil. In: SIMPÓSIO SOBRE MANEJO DA PASTAGEM, 12., 1995, Piracicaba. Anais... Piracicaba: FEALQ, 1995. p. 1-20.

BELARMINO, M. C. J. Rendimento e qualidade de forragem de Panicum maximum Jacq. cv. Tanzânia I em função da aplicação de superfosfato simples e sulfato de amônio. 2001. 94 p. Dissertação (Mestrado) - Universidade Federal de Lavras, Lavras, 2001.

CAMARGO, P. N. de; SILVA, O. Manual de adubação foliar. Piracicaba: Herba, 1975. 285 p.

CARVALHO, M. M.; MARTINS, C. E.; VERNEQUE, R. da S.; SIQUEIRA, C. Resposta de uma espécie de braquiária a fertilização com nitrogênio e potássio em um solo ácido.

Revista Brasileira de Ciência do Solo, Campinas, v. 15, n. 2, p. 195-200, maio/ago. 1991. 
COMISSÃO DE FERTILIDADE DO SOLO DO ESTADO DE MINAS GERAIS. Recomendações para o uso de corretivos e fertilizantes em Minas Gerais: 5 aproximação. Viçosa, 1999. 359 p.

COSTA, N. de L.; OLIVEIRA, J. R. da C. Produção de forragem e composição química de Panicum maximum cv. Tobiatã em diferentes idades de corte. In: REUNIÃO ANUAL DA SOCIEDADE BRASILEIRA DE ZOOTECNIA, 34., 1997, Juiz de Fora. Anais... Juiz de Fora: SBZ, 1997. p. $222-224$.

FAO. FAO. Disponível em: <http://www.fao.org>. Acesso em: 10 nov. 2000

FERREIRA, D. F. SISVAR - Sistema de Análise de Variância para Dados Balanceados. Versão 4.3. Lavras: DEX/UFLA, 2003.

FURTINI NETO, A. E.; VALE, F. R. do; RESENDE, A. V. de; GUILHERME, L. R. G.; GUEDES, G. A. de A. Fertilidade do solo. Lavras: FAEPE, 2001. 252 p.

HODGSON, J. Herbage production and utilization. In: . Grazing management: science in to practice. New York: Wiley, 1990. p. 38-54.
LEMAIRE, G.; CHAPMAN, D. Tissue flows in grazed plant communities. In: HODGSON, J.; JILIUS, A. W. (Eds.). The ecology and management of grazing systems. Guildford: CAB International, 1996. cap. 1, p. 3-36.

MATTOS, W. T. de; MONTEIRO, F. A. Respostas de braquiária brizantha a doses de potássio. Scientia Agricola, Piracicaba, v. 55, n. 3, p. 428-437, set./dez. 1998.

OLIVEIRA, M. A. de; PEREIRA, O. G.; GARCIA, R Rendimento e valor nutritivo do capim-tifton 85 (Cynodon spp.) em diferentes idades de rebrota. Revista Brasileira Zootecnia, Viçosa, v. 29, n. 6, p. 1949-1960, nov./dez. 2000.

RAIJ, B. V.Fertilidade do solo e adubação. Piracicaba: Ceres/ Potafos, 1991. 343 p.

SANTOS, P. M. Estudo de algumas características agronômicas de Panicum maximum (Jacq.) cvs. Tanzânia e Mombaça para estabelecer seu manejo. 1997. 62 f. Dissertação (Mestrado em Produção Animal e Pastagens) - Escola Superior de Agricultura Luiz de Queiroz, Piracicaba, 1997.

SILVA, D. J. Análise de alimentos: métodos químicos e biológicos. 2. ed. Viçosa: UFV, 1981. 166 p. 